www.nature.com/pj

\title{
Polymer reaction of poly( $p$-phenylene-ethynylene) by addition of decaborane: modulation of luminescence and heat resistance
}

\author{
Kenta Kokado and Yoshiki Chujo
}

Polymer reactions of poly(p-phenylene-ethynylene) (PPE) based on the addition reaction of decaborane to the carbon-carbon triple bond were successfully carried out. The platform polymer was synthesized through Sonogashira-Hagihara coupling polymerization. The effective introduction of the boron cluster, and thus the subsequent formation of $o$-carborane, was supported by ${ }^{1} \mathrm{H}$ and ${ }^{11} \mathrm{~B}$ nuclear magnetic resonance spectroscopies. The introduction rate of decaborane to the polymer main chain was proportional to the feed ratio of decaborane. Ultraviolet-visible absorption and photoluminescence studies illustrate the shortening of the effective $\pi$-conjugation length caused by the introduction of carborane clusters. Furthermore, the introduction of the boron cluster by the polymer reaction efficiently enhanced the heat resistance of PPE.

Polymer Journal (2010) 42, 363-367; doi:10.1038/pj.2010.13; published online 17 March 2010

Keywords: addition reaction; carborane; $\pi$-conjugated polymer; heat resistance; luminescence

\section{INTRODUCTION}

$\pi$-Conjugated polymers have attracted considerable attention for photonic and electronic applications, such as organic light-emitting diodes, photovoltaics, organic lasers and organic field-effect transistors, as well as other organic devices. ${ }^{1-6}$ Among various $\pi$-conjugated polymers, poly(p-phenylene-ethynylene)s (PPEs) are a class of the most promising polymers because of their high fluorescence quantum yield, stimuliresponsive emission and highly planarized structure. ${ }^{7-10} \mathrm{~A}$ large number of studies have demonstrated the synthesis and device fabrication of PPEs; however, it still remains a matter of research to enhance various properties.

An expedient way to improve the properties of $\pi$-conjugated polymers, for example, large molar absorption coefficient, highly efficient emission and nonlinear optical properties, is by hybridizing $\pi$-conjugated polymers with inorganic materials. ${ }^{11-17}$ For example, $\pi$-conjugated polymers containing polyhedral oligomeric silsesquioxanes or polyoxometalate have shown high thermal, mechanical, oxidationresistance and electrochemical properties, as well as heat resistance. ${ }^{18-24}$ Recently, we reported the synthesis of novel $\pi$-conjugated polymers with an icosahedral carborane cluster in their main chain, their great thermal durability and surprising optical properties, that is, aggregation-induced emission based on the molecular orbital of $o$-carborane..$^{25-32}$ Although the hybridization of $\pi$-conjugated polymers with inorganic clusters has given prominent results, the multistep synthesis of monomers containing inorganic clusters would have obstructed a thorough investigation in this field. One methodology to lessen the burden on synthesis is the polymer reaction of $\pi$-conjugated polymers. Several reports have described the polymer reaction of $\pi$-conjugated polymers and drastic modification of optical and/or thermal properties, ${ }^{33-36}$ while the variation is still limited. From this viewpoint, we focused attention on the addition reaction of decaborane to the carbon-carbon triple bond, known as a facile synthetic method, to obtain an $o$-carborane cluster. In this article, we present the efficient polymer reaction of PPEs by the addition reaction of decaborane and consequent changes in luminescent and thermal properties.

\section{EXPERIMENTAL PROCEDURE}

Instruments

${ }^{1} \mathrm{H}(400 \mathrm{MHz})$ and ${ }^{11} \mathrm{~B}(128 \mathrm{MHz})$ nuclear magnetic resonance (NMR) measurements were recorded on a JEOL JNM-EX400 instrument (JEOL Ltd., Tokyo, Japan). ${ }^{1} \mathrm{H}$ NMR spectra used $0.05 \%$ tetramethylsilane as an internal standard, and ${ }^{11} \mathrm{~B}$ NMR spectra were externally referenced to $\mathrm{BF}_{3} \cdot \mathrm{Et}_{2} \mathrm{O}$ at room temperature. Number-average molecular weight and molecular-weight distribution values were estimated on a TOSOH size exclusion chromatography system (TOSOH Corp., Tokyo, Japan) equipped with a polystyrene gel column (TOSOH TSKgel G3000HXL) using an ultraviolet detector (UV-8020) and refractive-index (RI-8020) detector at $40^{\circ} \mathrm{C}$. Thermogravimetric analysis was performed using a TG/DTA 6200 (SEIKO Instruments Inc., Chiba, Japan) with a heating rate of $10^{\circ} \mathrm{C} \mathrm{min}-1$ under dry air. Ultraviolet-visible spectra were recorded on a Shimadzu UV-3600 spectrophotometer (SHIMADZU Corp., Kyoto, Japan) at room temperature. Fluorescence emission spectra and absolute quantum yield by the integrating sphere method were recorded on a HORIBA Jobin Yvon Fluoromax-4 spectrofluorometer (HORIBA Jobin Yvon Inc., Edison, NJ, USA).

\section{Materials}

All synthetic procedures were performed under an argon atmosphere. Unless stated otherwise, all reagents were obtained from commercial 


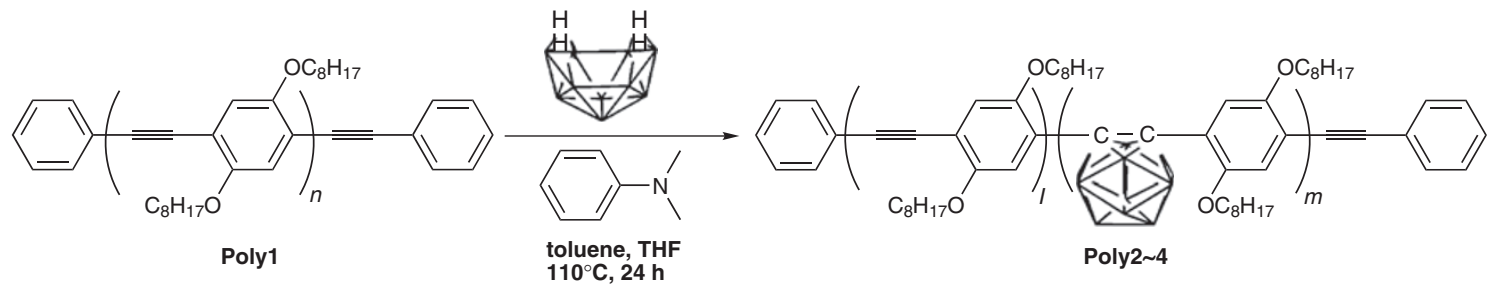

Scheme 1 Polymer reaction of a PPE with decaborane.

sources and used without further purification. Tetrahydrofuran (THF) and triethylamine were purified using a two-column solid-state purification system (Glasscontour System, Joerg Meyer, Irvine, CA, USA). 2,5-Bis(octyloxy)-1,4-diiodobenzene and 2,5-bis(octyloxy)-1,4diethynylbenzene were synthesized and characterized according to literature. ${ }^{37}$

\section{Synthesis of Poly1}

2,5-Bis(octyloxy)-1,4-diiodobenzene ( $1.47 \mathrm{~g}, 2.50 \mathrm{mmol}$ ), 2,5-bis(octyloxy)-1,4-diethynylbenzene (0.66 g, $2.25 \mathrm{mmol}), \mathrm{Pd}\left(\mathrm{PPh}_{3}\right)_{4}(146 \mathrm{mg}$, $125 \mu \mathrm{mol})$ and $\mathrm{CuI}(16 \mathrm{mg}, 125 \mu \mathrm{mol})$ were combined in anhydrous THF $(30 \mathrm{ml})$ and triethylamine $(15 \mathrm{ml})$. Ethynylbenzene $(110 \mu \mathrm{l}$, $0.50 \mathrm{mmol}$ ) was added to the reaction mixture, which was then refluxed for $24 \mathrm{~h}$. After polymerization, the reaction mixture was diluted with $\mathrm{CHCl}_{3}$ and washed with aqueous $\mathrm{NH}_{3}$ solution $(10 \mathrm{wt} \%)$, water and brine. The organic layer was dried over $\mathrm{MgSO}_{4}$ and concentrated. The residue was dissolved in a small amount of $\mathrm{CHCl}_{3}$ and reprecipitated from a large amount of methanol. The polymer was dried in vacuo to obtain Polyl as an orange powder. ${ }^{1} \mathrm{H}$ NMR $\left(\mathrm{CDCl}_{3}\right): \delta$ (p.p.m.) 7.57-7.51 (trace (2H), end capping Ar- $H$ ), 7.37-7.31 (trace (3H), end capping Ar- $H)$, 7.06-6.96 (2H, Ar- H), 4.12$3.93\left(4 \mathrm{H},-\mathrm{O}-\mathrm{CH}_{2}-\right), 1.93-1.78\left(4 \mathrm{H},-\mathrm{OCH}_{2}-\mathrm{CH}_{2^{-}}\right) 1.55-1.44(4 \mathrm{H}$, $\left.-\mathrm{OCH}_{2} \mathrm{CH}_{2}-\mathrm{CH}_{2}-\right), 1.44-1.07\left(16 \mathrm{H},-\left(\mathrm{CH}_{2}\right)-\right), 0.95-0.77\left(6 \mathrm{H},-\mathrm{CH}_{3}\right)$.

\section{General procedure of polymer reaction}

To Poly1 (35.7 mg, $100 \mu$ mol; poly1, $M_{\mathrm{n}}=4900, M_{\mathrm{w}} / M_{\mathrm{n}}=2.40$ ) placed in a dry glass ampule equipped with a magnetic stir bar were added decaborane $(610 \mu \mathrm{g}, 5 \mu \mathrm{mol})$ and $N, N$-dimethylaniline $(1200 \mu \mathrm{g}$, $10 \mu \mathrm{mol})$ dissolved in toluene $(2.5 \mathrm{ml})$ and THF $(2.5 \mathrm{ml})$, and then the solution was degassed by three freeze-evacuate-thaw cycles. The ampule was subsequently immersed in an oil bath preheated to $110^{\circ} \mathrm{C}$, and it was held for $24 \mathrm{~h}$ before being quenched by rapid cooling with liquid nitrogen. The reaction mixture was diluted in chloroform, and the insoluble product was filtered off. The filtrate was concentrated with a rotary evaporator and reprecipitated from a large excess of methanol. The resulting product isolated by filtration was dried under vacuum at room temperature to yield the corresponding polymer Poly2 as a brown powder with a $90 \%$ yield.

\section{RESULTS AND DISCUSSION}

\section{Synthesis and characterization}

PPE as a platform for the polymer reaction was synthesized by Sonogashira-Hagihara coupling polycondensation between 2,5bis(octyloxy)-1,4-diiodobenzene and 2,5-bis(octyloxy)-1,4-diethynylbenzene in the mixed solvent of THF-triethylamine. For the end group estimation of molecular weight in ${ }^{1} \mathrm{H}$ NMR spectroscopy, the feed ratio of the diiodo monomer, diethynyl monomer and ethynylbenzene (end group) was 10/9/2. From ${ }^{1} \mathrm{H}$ NMR spectroscopy, the number-average molecular weight was resolved as $5200(n \sim 14)$, and this result was in good agreement with that obtained by gel-permeation chromatography $\left(M_{\mathrm{n}}=4900\right)$, indicating that diiodo and diethynyl
Table 1 The results of the polymer reaction

\begin{tabular}{|c|c|c|c|c|c|c|}
\hline \multirow[b]{2}{*}{ Polymer } & \multicolumn{2}{|c|}{$\begin{array}{c}\text { Decaborane/monomer unit } \\
\left(\mathrm{mol} \mathrm{mol}^{-1}\right)\end{array}$} & \multirow[b]{2}{*}{$M_{n}^{a}$} & \multirow[b]{2}{*}{$M_{w}{ }^{a}$} & \multirow[b]{2}{*}{$M_{w} / M_{n}^{a}$} & \multirow[b]{2}{*}{ Yield $(\%)^{b}$} \\
\hline & Calculated & Observed & & & & \\
\hline Poly1 & 0 & 0 & 4900 & 12000 & 2.40 & - \\
\hline Poly2 & 0.05 & 0.05 & 4600 & 10700 & 2.33 & 90 \\
\hline Poly3 & 0.10 & 0.08 & 4500 & 12400 & 2.75 & 84 \\
\hline Poly4 & 0.20 & 0.14 & 3200 & 4200 & 2.56 & 76 \\
\hline Poly5 & 0.40 & - & - & - & - & - \\
\hline
\end{tabular}

a Calculated by ${ }^{1} \mathrm{H}$ nuclear magnetic resonance spectra.

bestimated by size exclusion chromatography on the basis of polystyrene standards in $\mathrm{CHCl}_{3}$. cIsolated yields after reprecipitation into $\mathrm{MeOH}$.

monomers underwent an effective palladium-catalyzed polymerization, that is, the expected polymer structure was obtained.

The polymer reaction of Poly1 was carried out with decaborane(14) in the mixed solvent of toluene-THF at $110^{\circ} \mathrm{C}$ for $24 \mathrm{~h}$ (Scheme 1). During the reaction, a small amount of dark brown precipitate was formed, which was practically insoluble in chloroform, and the amount of insoluble parts increased with increasing amounts of decaborane. The formation of insoluble parts is presumably responsible for the decrease in yield of the polymer reaction. ${ }^{38-40}$

Table 1 summarizes the results of the corresponding polymer reaction. The feed ratio of decaborane per triple bond was 0.05, 0.10, 0.20 and 0.40 for Poly2, Poly3, Poly4 and Poly5, respectively. Unfortunately, an excess production of insoluble parts prevented us from obtaining Poly5. The number-average molecular weight of Poly1-4 decreased with increasing feed ratio. The highly bent nature of the resulting $o$-carborane moieties in the polymer backbone and insoluble product more easily formed from higher molecular weight fragments is presumably responsible for the decrease in the numberaverage molecular weights of the polymers obtained. This notion is also supported by the decrease in yield with an increase in the feed ratio of decaborane.

The introduction of decaborane to the PPE main chain was confirmed by the ${ }^{1} \mathrm{H}$ NMR spectra of Poly1-4 normalized by the signal at 4.05 p.p.m. (-O- $\mathrm{CH}_{2-}$, Figure 1). Poly1 exhibited no signal in the area between 3.80 and 2.50 p.p.m., which is attributed to B-H signals in $o$-carborane. As a result of the polymer reaction, a signal increase was observed at around 3.5 p.p.m. (Poly2), and broadened peaks were finally observed at 3.70-2.60 p.p.m. (Poly4). Furthermore, ${ }^{11} \mathrm{~B}$ NMR spectra also showed broad peaks at $\sim 0$ to 10 p.p.m. These peaks are assigned to the presence of the $o$-carborane structure, indicating that the polymer reaction successfully introduced decaborane into the PPE main chain. The observed ratios of decaborane per monomer unit were slightly lower than the feed ratios, and the estimated reaction rates were more than $70 \%$, which is consistent with previous reports. ${ }^{38,39}$ 


\section{Optical properties}

To investigate the optical properties of polymers Poly1-4, ultravioletvisible absorption and fluorescence experiments were carried out in THF (Figure 2). Poly1 exhibited an absorption maxima at $431 \mathrm{~nm}$, similar to the reported value. ${ }^{37,41-43}$ The introduction of decaborane into the PPE main chain resulted in the hypsochromic shift of the absorption maxima (Poly2: $428 \mathrm{~nm}$, Poly3: $425 \mathrm{~nm}$, Poly4: $419 \mathrm{~nm}$, Figure $2 \mathrm{a}$ ), probably due to the shortening of the effective $\pi$-conjugation length caused by the conversion of triple bonds. Poly1-4 showed a light-blue emission in the solution state (Figure 2b), and the emission maxima stayed at around $470 \mathrm{~nm}$ with shoulder peaks at $497 \mathrm{~nm}$ (Table 2). The emission maxima of Poly1-4 gave $40-50 \mathrm{~nm}$ Stokes shift values consistent with the reported PPEs. The contribution of the shoulder peak and Stokes shift value in the fluorescence spectra gradually increased with the increase in the feed ratio of decaborane, indicating the existence of fluorescence from the intramolecular charge transfer state.

In the mixed solvent of THF- $\mathrm{H}_{2} \mathrm{O}$ (1:99), the absorption maxima of Poly1-4 showed a slightly bathochromic shift compared with those in THF solution (Poly1: $446 \mathrm{~nm}$, Poly2: $439 \mathrm{~nm}$, Poly3: $436 \mathrm{~nm}$, Poly4: $433 \mathrm{~nm}$ ), and more importantly, a new shoulder in the

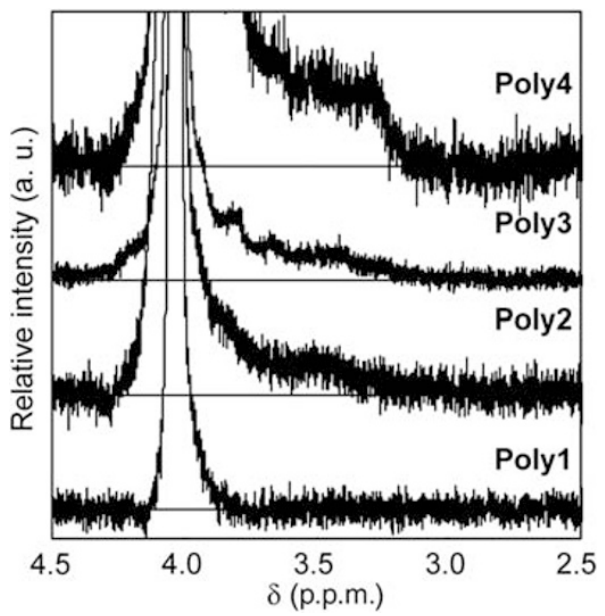

Figure $1{ }^{1} \mathrm{H}$ NMR spectra of Poly1-4 in $\mathrm{CDCl}_{3}$. Heights were normalized by the signal at 4.05 p.p.m. $\left(-0-\mathrm{CH}_{2}^{-}\right)$. absorption spectra appeared at around $475 \mathrm{~nm}$ (Figure 3a). The contribution of the new shoulder peaks diminished with increasing feed ratio. One possible reason for the appearance of the shoulder peak is the formation of an aggregate structure in the mixed solvent of THF- $\mathrm{H}_{2} \mathrm{O}$ (1:99). This explanation was also supported by the fluorescence spectra of Poly1-4 in the mixed solvent of THF- $\mathrm{H}_{2} \mathrm{O}$ (1:99, Figure $3 \mathrm{~b}$ ). The emission maxima of these polymers appeared at longer wavelengths with lower feed ratios (Poly1: $568 \mathrm{~nm}$, Poly2: 542 nm, Poly3: 536 nm, Poly4: 529 nm). These observations indicate that the introduction of carborane clusters resulted in the shortening of the effective $\pi$-conjugation length of Poly1-4.

Poly4 exhibited the broadest fluorescence spectrum in a range of $450-750 \mathrm{~nm}$ in the poor solvent, probably due to the contribution of the intramolecular charge-transfer state derived from $o$-carborane moieties. The fluorescence spectra of Poly1-4 in the film state demonstrated the same tendency as those in the poor solvent (Figure 4). The contribution of emission at longer wavelengths $(\sim 750 \mathrm{~nm})$ in the fluorescence spectra increased with an increasing feed ratio of decaborane, whereas the emission maxima appeared at around the same position as those measured in the poor solvent (Poly1: $538 \mathrm{~nm}$ with shoulder band at $563 \mathrm{~nm}$, Poly2: $534 \mathrm{~nm}$ with shoulder band at $549 \mathrm{~nm}$, Poly3: $534 \mathrm{~nm}$, Poly4: $516 \mathrm{~nm}$ ). These data support the introduction of decaborane as a possible cause of the intramolecular charge-transfer state in the fluorescence spectra and show the applicability of this polymer reaction to tune the optical properties of PPE.

\section{Thermal properties}

Boron-containing compounds are typically known as cheap and lowtoxic flame retardants because a surface layer of protective char

Table 2 Ultraviolet-visible absorption and photoluminescence properties of Poly1-4

\begin{tabular}{lcccc}
\hline Polymer & $\lambda_{\max }(\mathrm{nm})$ & $\varepsilon \lambda_{\max }\left(\mathrm{M}^{-1} \mathrm{Cm}^{-1}\right)$ & $P L(\mathrm{~nm})$ & Stokes shift (nm) \\
\hline Poly1 & 431 & 36000 & 471,496 & 40 \\
Poly2 & 428 & 22000 & 471,497 & 43 \\
Poly3 & 425 & 69000 & 471,497 & 46 \\
Poly4 & 419 & 56400 & 469,497 & 50
\end{tabular}

a Measured in tetrahydrofuran solution $\left(1.0 \times 10^{-5} \mathrm{M}\right)$ at room temperature.
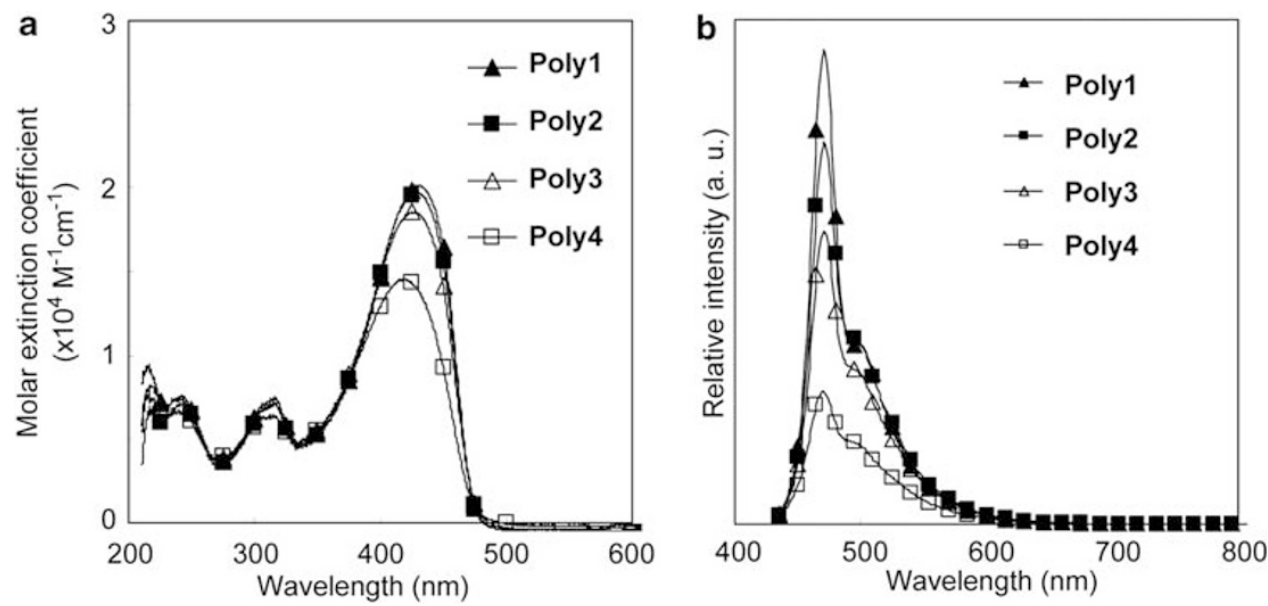

Figure 2 (a) Ultraviolet-visible absorption and (b) fluorescence spectra of Poly1-4 THF solution $\left(1.0 \times 10^{-5} \mathrm{M}\right)$. 

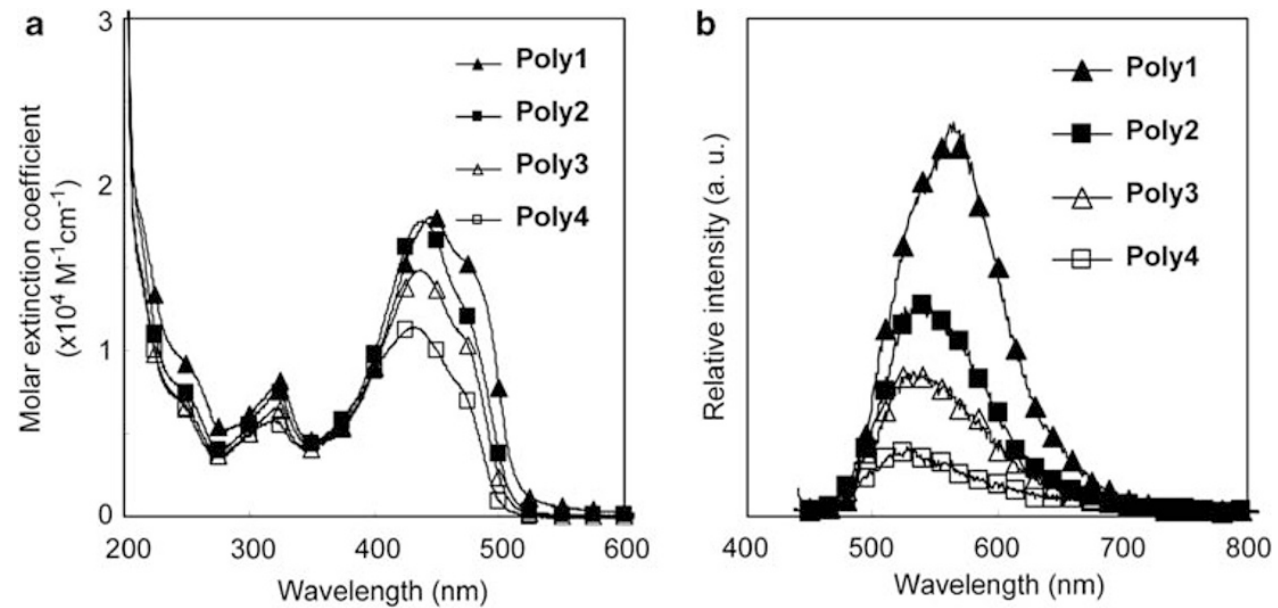

Figure 3 (a) Ultraviolet-visible absorption and (b) fluorescence spectra of Poly1-4 in the mixed solvent of THF- $\mathrm{H}_{2} \mathrm{O}\left(1: 99,1.0 \times 10^{-5} \mathrm{M}\right)$.

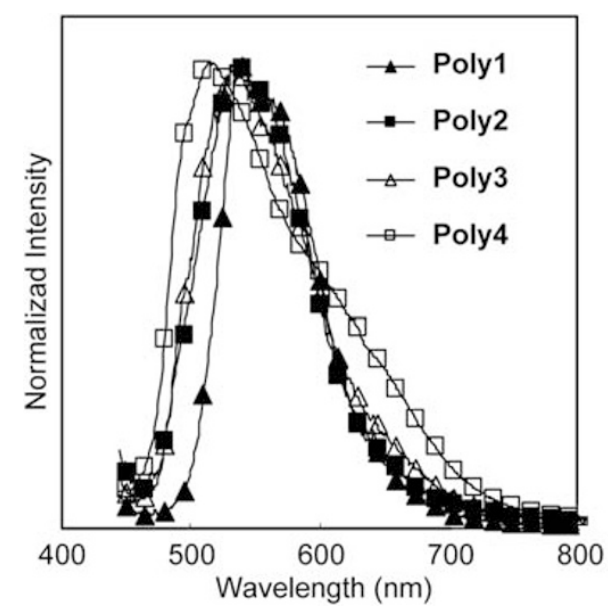

Figure 4 Fluorescence spectra of Poly1-4 in the film state.

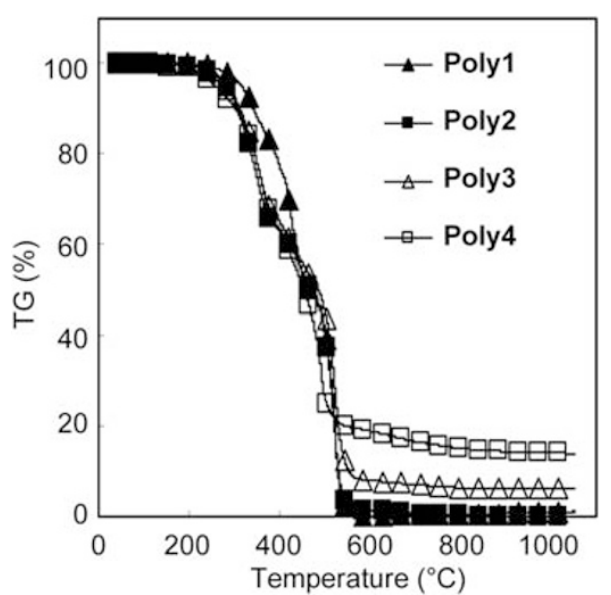

Figure 5 Thermogravimetric analysis thermograms of Poly1-4 under dry air.

formed on heating acts as a barrier against oxygen and prevents the oxidation of carbon. ${ }^{44-47}$ Information on the thermal properties of the obtained polymers was obtained by thermogravimetric analysis, as
Table 3 Thermal properties of Poly1-4

\begin{tabular}{|c|c|c|c|c|}
\hline \multirow[b]{2}{*}{ Polymer } & \multicolumn{2}{|c|}{ Ceramic yield (\%) } & \multirow[b]{2}{*}{$T_{d 5}\left({ }^{\circ} \mathrm{C}\right)^{\mathrm{c}}$} & \multirow[b]{2}{*}{$T_{d 50}\left({ }^{\circ} \mathrm{C}\right)^{\mathrm{d}}$} \\
\hline & Calculated $^{\mathrm{a}}$ & Observed $^{b}$ & & \\
\hline Poly1 & 0 & 0 & 316.9 & 466.8 \\
\hline Poly2 & 4.8 & 1.11 & 283.6 & 468.5 \\
\hline Poly3 & 7.59 & 6.30 & 282.1 & 485.5 \\
\hline Poly4 & 12.71 & 13.92 & 258.1 & 453.7 \\
\hline
\end{tabular}

shown in Figure 5. The introduction of $o$-carborane moieties into the polymer main chain led to an extreme resistance to heat and an improvement in ceramic yields on thermolysis to $1050^{\circ} \mathrm{C}$ (Table 3) because of the excellent char-forming property of compounds containing carborane. The 5\% degradation temperature decreased with increasing $o$-carborane content, probably due to the promotion of carbonization and dehydration caused by boron. These findings suggest that the polymer reaction efficiently enhanced the heat resistance of PPE.

\section{CONCLUSION}

In summary, we synthesized PPE through Sonogashira-Hagihara coupling polymerization as a platform and successfully carried out subsequent polymer reactions by the addition of decaborane. The effective introduction of boron clusters, and thus the formation of $o$-carborane, was confirmed by ${ }^{1} \mathrm{H}$ and ${ }^{11} \mathrm{~B}$ NMR spectroscopies, and the introduction rate was proportional to the feed ratio of decaborane. Ultraviolet-visible absorption and photoluminescence studies reveal the shortening of the effective $\pi$-conjugation length caused by the introduction of carborane clusters; however, the polymer with the highest $o$-carborane content showed indications of an intramolecular charge-transfer state. Moreover, the polymer reaction efficiently improved the heat resistance of PPE. Further work is currently underway to design the polymer reaction with greater amounts of decaborane. 
1 Skothim, T. A., Elsenbaumer, R. L. \& Reynolds, J. Handbook of Conducting Polymers, 2nd edn,Marcel Dekker: New York, (1997).

2 Burroughes, J. H., Bradley, D. D. C., Brown, A. R., Marks, R. N., Mackay, K., Friend, R. H., Burns, P. L. \& Holmes, A. B. Light-emitting diodes based on conjugated polymers. Nature 347, 539-541 (1990).

3 Gustafsson, G., Cao, Y., Treacy, G. M., Klavetter, F., Colaneri, N. \& Heeger, A. J. Flexible light-emitting diodes made from soluble conducting polymer. Nature 357, 477-479 (1992).

4 Gross, M., Muller, D. C., Nothofer, H.- G., Scherf, U., Neher, D., Brauchle, C. \& Merrholz, K. Improving the performance of doped $\pi$-conjugated polymers for use in organic light-emitting diodes. Nature 405, 661-665 (2000).

5 Sirringhaus, H., Tessler, N. \& Friend, R. H. Integrated optoelectronic devices based on conjugated polymers. Science 280, 1741-1744 (1998).

6 Babel, A. \& Jenekhe, S. A. High electron mobility in ladder polymer field-effect transistors. J. Am. Chem. Soc. 125, 13656-13657 (2003).

7 McQuade, D. T., Pullen, A. E. \& Swager, T. M. Conjugated polymer-based chemical sensors. Chem. Rev. 100, 2537-2574 (2000).

8 Thomas\#\#III, S. W., Joly, G. D. \& Swager, T. M. Chemical sensors based on amplifying fluorescent conjugated polymers. Chem. Rev. 107, 1339-1386 (2007)

9 Bunz, U. H. F. Poly(aryleneethynylene)s: syntheses, properties, structures, and applications. Chem. Rev. 100, 1605-1644 (2000).

10 Bunz, U. H. F. Synthesis and structure of PAEs. Adv. Polym. Sci. 177, 1-52 (2005).

11 Clark, A. P.- Z., Shen, K.- F., Rubin, Y. F. \& Tolbert, S. H. An amphiphilic poly(phenylene ethynylene) as the structure-directing agent for periodic nanoscale silica composite materials. Nano Lett. 5, 1647-1652 (2005).

12 Winter, A., Friebe, C., Hager, M. D. \& Schubert, U. S. Advancing the solid state properties of metallo-supramolecular materials: poly(å-caprolactone) modified $\pi$-conjugated Bis(terpyridine)s and their $\mathrm{Zn}(\mathrm{II})$ based metallo-polymers. Macromol. Rapid Commun. 29, 1679-1686 (2008).

13 Wung, C. J., Pang, Y., Prasad, P. N. \& Karasz, F. E. Poly(p-phenylene vinylene)-silica composite: a novel sol-gel processed non-linear optical material for optical waveguides. Polymer 32, 605-608 (1991).

14 Kubo, M., Takimoto, C., Minami, Y., Uno, T. \& Ito, T. Incorporation of $\pi$-conjugated polymer into silica: preparation of poly[2-methoxy-5-(2-ethylhexyloxy)-1,4-phenylenevinylene]/silica and poly(3-hexylthiophene)/silica composites. Macromolecules $\mathbf{3 8}$, 7314-7320 (2005).

15 Kokado, K. \& Chujo, Y. Poly(p-phenyleneethynylene)-silica gel hybrids without any compatibilizer. Chem. Lett. 37, 732-733 (2008).

16 Kokado, K. \& Chujo, Y. Homogeneous anionic ppe hybrids with silica gel. J. Polym. Sci., Part A: Polym. Chem. 46, 3749-3755 (2008).

17 Ogoshi, T. \& Chujo, Y. Synthesis of amorphous and nano-structured cationic polyacetylene/silica hybrids by using ionic interaction. Macromolecules 38, 9110-9116 (2005).

18 Lu, M., Xie, B., Kang, J., Chen, F.- C., Yang, Y. \& Peng, Z. Synthesis of main-chain polyoxometalate-containing hybrid polymers and their applications in photovoltaic cells. Chem. Mater. 17, 402-408 (2005).

19 Xu, B., Lu, M., Kang, J., Wang, D., Brown, J. \& Peng, Z. Synthesis and optical properties of conjugated polymers containing polyoxometalate clusters as side-chain pendants. Chem. Mater. 17, 2841-2851 (2005).

20 Miyake, J. \& Chujo, Y. Thermally stabilized blue luminescent poly( $p$-phenylene)s covered with polyhedral oligomeric silsesquioxanes. Macromol. Rapid Commun. 29, 86-92 2008.

21 Miyake, J. \& Chujo, Y. Persistent and emission color tunable poly(phenylene-ethynylene)s covered with polyhedral oligomeric silsesquioxanes. J. Polym. Sci., Part A: Polym. Chem. 46, 8112-8116 (2008).

22 Miyake, J. \& Chujo, Y. A Hybrid-Type, chiral $\pi$-conjugated polymer wrapped with polyhedral oligomeric silsesquioxanes. J. Polym. Sci., Part A: Polym. Chem. 46, 6035-6040 (2008)

23 Miyake, J., Sawamura, T., Kokado, K. \& Chujo, Y. Amphiphilic hybrid $\pi$-conjugated polymers containing polyhedral oligomeric silsesquioxanes. Macromol. Rapid Commun. 30, 1559-1563 (2009)

24 Simon, Y. C., Peterson, J. J., Mangold, C., Carter, K. R. \& Coughlin, E. B. Synthesis of polyfluorenes with pendant silylcarboranes. Macromolecules 42, 512-516 (2009).
25 Kokado, K. \& Chujo, Y. Emission via aggregation of alternating polymers with ocarborane and p-phenylene-ethynylene sequences. Macromolecules 42, 1418-1420 (2009).

26 Kokado, K., Tokoro, Y. \& Chujo, Y. Luminescent $m$-carborane-based $\pi$-conjugated polymer. Macromolecules 42, 2925-2930 (2009).

27 Kokado, K., Tokoro, Y. \& Chujo, Y. Luminescent and axially chiral $\pi$-conjugated polymers linked by carboranes in the main chain. Macromolecules 42, 9238-9242 (2009).

28 Luo, J., Xie, Z., Lam, J. W. Y., Cheng, L., Tang, B. Z., Chen, H., Qiu, C., Kwok, H. S., Zhan, X., Liu, Y. \& Zhu, D. Aggregation-induced emission of 1-methyl-1,2,3,4,5- pentaphenylsilole. Chem. Commun. 37, 1740-1741 (2001).

29 Hong, Y., Lam, J. W. Y. \& Tang, B. Z. Aggregation-induced emission: phenomenon mechanism and applications. Chem. Commun. 45, 4332-4353 (2009).

30 Liu, J., Lam, J. W. Y. \& Tang, B. Z. Acetylenic Polymers: Syntheses, Structures, and Functions. Chem. Rev. 109, 5799-5867 (2009).

31 Peterson, J. J., Simon, Y. C., Coughlin, E. B. \& Carter, K. R. Polyfluorene with p-carborane in the backbone. Chem. Commun. 45, 4950-4952 (2009).

32 Peterson, J. J., Werre, M., Simon, Y. C., Coughlin, E. B. \& Carter, K. R. Carboranecontaining polyfluorene: o-carborane in the main chain. Macromolecules 42, 8594-8598 (2009).

33 Michinobu, T. Click-type reaction of aromatic polyamines for improvement of thermal and optoelectronic properties. J. Am. Chem. Soc. 130, 14074-14075 (2008).

34 Michinobu, T., Kumazawa, H., Noguchi, K. \& Shigehara, K. One-step synthesis of donoracceptor type conjugated polymers from ferrocene-containing poly(aryleneethynylene)s. Macromolecules 42, 5903-5905 (2009).

35 Hayashi, S., Inagi, S. \& Fuchigami, T. Synthesis of 9-substituted fluorene copolymers via chemical and electrochemical polymer reaction and their optoelectronic properties. Macromolecules 42, 3755-3760 (2009).

36 Inagi, S., Hayashi, S., Hosaka, K. \& Fuchigami, T. Facile functionalization of a thiophenefluorene alternating copolymer via electrochemical polymer reaction. Macromolecules 42, 3881-3883 (2009).

37 Weder, C. \& Wrighton, M. S. Efficient solid-state photoluminescence in new poly(2,5dialkoxy-p-phenyleneethynylene)s. Macromolecules 29, 5157-5165 (1996).

38 Safronov, A. V., Dolgushin, F. M., Petrovskii, P. V. \& Chizhevsky, I. T. Low-temperature ' $1,21,7$ ' isomerization of sterically crowded icosahedral closo- $\left(\left(2,3,8-\eta^{3}\right):\left(5,6-\eta^{2}\right)\right.$ norbornadien-2-yl)rhodacarborane via the formation of a pseudocloso intermediate. Molecular structures of $\left[3,3-\left(\left(2,3,8-\eta^{3}\right):\left(5,6-\eta^{2}\right)-\mathrm{C}_{7} \mathrm{H}_{7} \mathrm{CH}_{2}\right)-1,2-\left(4^{\prime}-\mathrm{MeC}_{6} \mathrm{H}_{4}\right)_{2}-3,1,2-\right.$ pseudocloso- $\left.\mathrm{RhC}_{2} \mathrm{~B}_{9} \mathrm{H}_{9}\right]$ and $1,21,7$ isomerized products. Organometallics 24, 2964-2970 (2005).

39 Fox, M. A., Howard, J. A. K., MacBride, H., Mackinnon, A. \& Wade, K. Big macrocyclic assemblies of carboranes (big MACs): synthesis and crystal structure of a macrocyclic assembly of four carboranes containing alternate ortho- and meta-carborane icosahedra linked by para-phenylene units. J. Organomet. Chem. 680, 155-164 (2003).

40 Ernest, R. L., Quintana, W., Rosen, R., Carroll, P. J. \& Sneddon, L. G. Reactions of decaborane(4) with silylated acetylenes synthesis of the new monocarbon carborane 9- $\mathrm{Me}_{2} \mathrm{~S}-7-\left[\left(\mathrm{Me}_{3} \mathrm{Si}\right)_{2} \mathrm{CH}\right]-\mathrm{CB}_{10} \mathrm{H}_{11}$. Organometallics 6, 80-88 (1987).

41 Palmans, A. R. A., Smith, P. \& Weder, C. Polarizing energy transfer in photoluminescent conjugated polymers with covalently attached sensitizers. Macromolecules $\mathbf{3 2}$, 4677-4685 (1999).

42 Giardina, G., Rosi, P., Ricci, A. \& Lo Sterzo, C. An efficient one-pot access to poly(arylene ethynylene) homopolymers: use of the $\mathrm{Bu}_{3} \mathrm{Sn}$-moiety as a recyclable carrier to introduce the ethynyl unit into the chain. J. Polym. Sci., Part A: Polym. Chem. 38, 2603-2621 (2000).

43 Liu, X., Zhu, M., Chen, S., Yuan, M., Guo, Y., Song, Y., Liu, H. \& Li, Y. Organic-inorganic nanohybrids via directly grafting gold nanoparticles onto conjugated copolymers through the diels-alder reaction. Langmuir 24, 11967-11974 (2008).

44 Lu, S.- Y. \& Hamerton, I. Recent developments in the chemistry of halogen-free flame retardant polymers. Prog. Polym. Sci. 27, 1661-1712 (2002).

45 González-Campo, A., Boury, B., Teixidor, F. \& Núñez, R. Carboranyl units bringing unusual thermal and structural properties to hybrid materials prepared by solgel process. Chem. Mater. 18, 4344-4353 (2006).

46 Ichitani, M., Yonezawa, K., Okada, K. \& Sugimoto, T. Silyl-carborane hybridized diethynylbenzene-silylene polymers. Polym. J. 31, 908-912 (1999).

47 Kimura, H., Okita, K., Ichitani, M., Sugimoto, T., Kuroki, S. \& Ando, I. Structural study of silylcarborane hybrid diethynylbenzenesilylene polymers by high-resolution solidstate ${ }^{11} \mathrm{~B},{ }^{13} \mathrm{C}$, and ${ }^{29} \mathrm{Si}$ NMR spectroscopy. Chem. Mater. 15, 355-362 (2003). 